\title{
A Dimensão Territorial no Planejamento do Desenvolvimento Turístico no Brasil: modelo do pólo de crescimento versus modelo territorialista e endógeno
}

\author{
The Territorial Dimension in Tourism Development Planning in \\ Brazil: a centralized development model versus a territorial \\ and endogenous model
}

\section{Jorge Antonio Santos Silva'}

\begin{abstract}
RESUMO: Este texto analisa a dimensão territorial no planejamento do desenvolvimento turístico comparando dois modelos de crescimento regional: o do pólo de crescimento e o territorialista e endógeno. A comparação teórica é efetuada tendo como pano de fundo o modelo que vem sendo adotado no Brasil desde meados da década de 1990, centrado na implantação de "pólos turísticos" regionalizados no país. O modelo do pólo de crescimento, que inspira os "pólos turísticos", privilegia os aspectos vinculados à função de especialização regional, no caso, o turismo. Sua implementação acontece atrelada a investimentos exógenos que não utilizam, numa escala otimizada, recursos produtivos de base local. Já o modelo territorialista e endógeno preconiza a prevalência do território sobre a função, sendo considerado, portanto, mais apropriado ao planejamento do desenvolvimento turístico, por propiciar um mais efetivo grau de endogeneização dos benefícios socioeconômicos gerados no processo.
\end{abstract}

PALAVRAS-CHAVE: análise territorial do turismo; planejamento e crescimento regional; desenvolvimento turístico.

ABSTRACT: This paper analyzes territorial factors in tourism development planning, comparing two models of regional growth: the centralized

1. Doutor em Ciências da Comunicação - Área de Concentração Turismo pela ECA/Us!; mestre em Administração pela UFBA; bacharel em Ciências Econômicas pela UCSAL e em Administração de Empresas pela EAEBA. Consultor em Turismo. Professor da Universidade Salvador - Unifacs, Faculdades Jorge Amado e Faculdades Hélio Rocha. Contato: Rua Padre Feijó, 597/1104 - 40110-170 - Salvador-BA; e-mail: jantss@globo.com. 
tourism development zone model, and the territorial and endogenous model. The theoretical analysis is carried out against the backdrop of the development model that has been implemented in Brazil since the mid-1990s. This model is based on the creation of regionalized "tourism development zones", The development zone growth model, that inspired the "development zones", highlights aspects related to the role of regional specialization, in this case, tourism. Its implementation is based on exogenous investments that don't use, on an optimized scale, local productive resources. On the other hand, the territorial and endogenous model focuses on local resources and their relationship with tourism development in the territory itself. The latter is considered more appropriate to tourism development planning because it leads to a higher degree of endogenization of the socio-economic benefits generated by the development process.

KEYWORDS: territorial analysis of the tourism; planning and regional growth; tourism development.

\section{Introdução}

No texto que ora se apresenta, analisa-se a dimensão territorial do desenvolvimento turístico tomando-se a região como objeto de estudo e contrapondose dois modelos de crescimento regional. De um lado, o modelo do pólo decrescimento, cuja base teórica foi formulada por François Perroux; de outro, o modelo territorialista e endógeno, sob a abordagem conceitual estruturada por John Friedmann e Clyde Weaver, com o objetivo de contextualizar-se, comparativa e criticamente, a sua utilização no planejamento do desenvolvimento turístico regional, tendo como pano de fundo o atual modelo adotado no Brasil, fundamentado na implantação de "pólos turísticos" regionalizados.

Ao se relacionarem as noções de espaço e região com o turismo, deve-se ter em conta que o mesmo, em sua concretização, caracteriza-se por ser uma atividade fortemente territorializada, ou seja, se as pessoas não se deslocarem de seu entorno habitual de residência para um local eleito como objeto de visitação, ficando um determinado período de tempo fisicamente presentes nesse local, o turismo não acontece.

O destino turístico e seu entorno regional podem configurar um espaço geográfico que tenha o turismo como sua função de especialização econômica. No planejamento do desenvolvimento turístico de um espaço geográfico assim configurado, não se devem privilegiar apenas os aspectos funcionais envolvidos.

A noção de território como um espaço socialmente construído e organizado deve ser o elemento-chave e norteador do processo de planejamento, buscando- se, desse modo, privilegiar os aspectos essenciais conducentes ao desenvolvimento turístico de base endógena: os recursos humanos, a capacidade empresarial e tecnológica, a estrutura produtiva - dotada de uma apropriada diversificação de atividades econômicas "encadeadas" -, o capital - físico, institucional e social -, enfim, o conjunto de recursos "localizados" que conformam o território no qual se efetiva a "consumação" turística.

Nesse sentido, entende-se o modelo territorialista e endógeno de desenvolvimento regional como sendo mais adequado que o modelo do pólo de crescimento para efeito do planejamento do desenvolvimento turístico, com o território devendo prevalecer sobre a função, que a ele deve estar incorporada e, nessa dimensão, ser analisada. Desse modo, acredita-se que o turismo, de fato, poderá cumprir um papel articulador e indutor do crescimento e desenvolvimento regional, atuando de forma agregada e integrada com as demais atividades econômicas já existentes, bem como com as que possam por ele ser viabilizadas no entorno regional objeto do planejamento.

Levando-se em conta que o planejamento deve ser considerado uma atividade endógena, aliado à complexidade envolvida na tentativa de estimular o desenvolvimento regional tendo o turismo como função de especialização, desde quando é marcado por um elevado nível de territorialidade, o Estado assume relevante função nesse processo.

No modelo de desenvolvimento turístico prevalecente no Brasil, focado na constituição de "pólos turísticos" regionalizados, considera-se que o papel do Estado no planejamento desse desenvolvimento tem deixado a desejar, quando se considera o efetivo grau de endogeneização dos seus resultados.

Ao privilegiar a função e implementar o processo à mercê de decisões e investimentos exógenos aos âmbitos local e regional, relega-se o território e todos os elementos que o integram, particularmente os ambientais e os sociais, a um plano secundário. Por conseqüência, acarreta-se uma diversidade de custos para a sociedade e o território, mitigando-se os impactos positivos e os benefícios socioeconômicos derivados do desenvolvimento turístico pela não-utilização, em escala otimizada, dos recursos de base local da região objeto do processo de planejamento.

Nessa perspectiva, ao comparar os dois modelos teóricos de crescimento regional, é fundamental que se tenha bem claras as noções de espaço, região e território que irão orientar o foco e o âmbito do planejamento em termos geográficos, econômicos e sociais.

Conforme Lopes (2002), não se devem confundir as noções de espaço e região. $\mathrm{O}$ espaço, para o autor, pode ser definido a partir de um conjunto de dados econômicos localizados, sendo que tais localizações podem ser dispersas, consi- 
derando que são as características e a natureza das relações de interdependência que dão unidade ao espaço. Já a região precisa ser definida de uma forma mais restrita, não em função de fatores relacionados à dimensão, mas referidos a razões de contigüidade, ou seja, os elementos que compõem uma região têm de se localizar de forma contígua.

Todo sistema territorial pode ser representado, de acordo com Furió Blasco (1994), como resultado da união e da costura de subsistemas funcionais. A. Cunha identificou sete componentes desse sistema, cujo conjunto Furió Blasco denominou "matriz funcional" do sistema territorial: subsistemas humano, cultural, tecnológico, econômico, espacial, político e ecológico.

Portanto, o território pode ser definido como

um conjunto formado por uma sociedade e o espaço que ela organiza. A noção de território engloba, pois, a noção de espaço, mas não se confunde com ela. Considera-se, aqui, o território como um conjunto dinâmico, delimitado por uma fronteira, na qual se combinam e relacionam os elementos físicos e humanos [...]. A diferenciação territorial é o resultado de um processo que conduz os atores sociais a organizarem, administrarem e apropriarem-se do espaço. [...] A noção de território manifesta, explicitamente, a existência de uma organização social, política e econômica que organiza e ordena o espaço [tradução livre nossa] (Cunha, 1988 apud Furió Blasco, 1994).

\section{A configuração espacial e territorial do turismo}

O turismo constitui, indubitavelmente, um fato social e econômico que se manifesta claramente no espaço. Seu caráter territorial, segundo Ivars (2003), é determinado pelo

deslocamento de pessoas, desde seu lugar de residência, a espaços que reúnem determinadas condições para satisfazer as diferentes motivações turísticas. Portanto, os fluxos turísticos implicam a existência de uma série de efeitos territoriais de diversa natureza, tanto nas áreas geográficas de trânsito como nas de destino [tradução livre nossa].

A delimitação das áreas de destino se realiza, conforme Ivars, a partir de sua função turística, de sua especialização em uma atividade econômica com evidentes efeitos territoriais. A satisfação da demanda turística torna-se possível mediante a existência, nas áreas de destino, de um sistema produtivo que gere rentabilidade econômica e social.
Não se trata, portanto, de um sistema produtivo convencional porque engloba bens públicos (geralmente, recursos naturais), infra-estruturas, empresas turísticas e não especificamente turísticas e, inclusive, a imagem do próprio destino. O sistema produtivo encontra sua unidade no destino turístico, denominador comum de bens e serviços diversos que configuram a experiência turística, na identidade do destino como elemento aglutinador e nas relações interempresariais, fundamentalmente entre as empresas turísticas e suas auxiliares. Além do mais, no cumprimento de sua função turística, gera distintos impactos que afetam tanto o sistema territorial como a própria produção turística (a degradação ambiental de uma praia não implica unicamente a deterioração do sistema territorial, mas também da competitividade da função turística do território) [tradução livre nossa] (Ivars, 2003).

A dispersão e relativa indefinição no uso dos conceitos referidos ao espaço turístico, de acordo com Ivars, torna aconselhável uma sistematização prévia que parte da redução do espaço turístico a três unidades básicas que desempenhem uma função turística, apesar de o seu grau de complexidade e extensão territorial ser distinto.

As três unidades territoriais básicas consideradas pelo autor identificam-se com os conceitos de complexos turísticos integrados, espaços de destino turístico e regiōes turísticas.

Os complexos turísticos integrados, de acordo com Ivars, cumprem autonomamente a função turística (por exemplo, Club Mediterranée) e se distinguem por sua menor extensão territorial; por uma concepção unitária que lhes confira caráter de produto integral - alojamento mais atividades de entretenimento; por uma clara orientação para segmentos de mercado determinados de acordo com o conceito de negócio selecionado; e pelo papel praticamente exclusivo do turismo como atividade econômica do território que ocupa, normalmente segregado, formal e funcionalmente, do sistema territorial no qual se insere, na condição de um "enclave turístico".

Já os espaços de destino turístico, segundo o autor, requerem a conjunção de uma série de empresas e serviços para desenvolver sua função turística dentro de um raio que pode alcançar desde um núcleo de povoamento até um âmbito subregional (por exemplo, um destino turístico de litoral ou um núcleo rural com oferta turística).

Esses espaços se identificam com destinos ou municípios turísticos, diferindo, formal e funcionalmente, dos complexos turísticos integrados, que podem se constituir em mais um elemento desses espaços. Nos espaços de destino, a função turística não é a única; embora possa ser a predominante, eles não correspondem a uma concepção unitária e sua oferta turística se nutre de uma diversidade de componentes dependentes de uma pluralidade de agentes. 
O destino turístico constitui-se, simultaneamente, em espaço de produção e de consumo. Nesse contexto, a especialização turística é obtida por meio das relações de complementaridade e concorrência com outros setores produtivos.

Considera-se, com Ivars, que o município - constituído pelos elementos território, população e organização - reúne em grande parte as características definidoras dos espaços de destino turístico, quando a atividade do turismo é um componente predominante ou relativamente significativo de sua estrutura territorial e socioeconômica, contando com a presença de fatores de atração, concentração de oferta e serviços turísticos, e, em geral, imagem diferenciada. Porém, segundo o autor, o município não delimita o espaço turístico, pois este se configura pelos padrões de localização das atividades turísticas, pelas pautas de consumo dos segmentos de demanda e pela imagem projetada e percebida do território.

Ainda segundo Ivars, a configuração do espaço turístico, a partir dos elementos que integram o destino turístico, resulta, de um lado, da apropriação dos recursos territoriais por parte das empresas turísticas, visando a obter a máxima rentabilidade de seus investimentos e aproveitando as externalidades positivas dos bens livres e públicos que atraem a demanda turística, e, de outro lado, da apropriação dos recursos naturais que realizam os consumidores turísticos para obter uma experiência satisfatória.

Ambas as dinâmicas, de produção e consumo, não dariam origem, por si mesmas, a um espaço turístico funcionalmente coeso, o que se viabiliza por intermédio da participação pública com suas diferentes formas de intervenção, assim condicionando a produção do espaço turístico.

A regiāo turística é outro conceito utilizado indistinta e indiferenciadamente para designar espaços de distintas características. Ivars (2003) adota a seguinte definição de região turística:

[...] uma unidade territorial básica do espaço turístico, na qual podem integrar-se as outras unidades territoriais diferenciadas (complexos turísticos integrados e espaços de destino turístico) e que apresentam certo grau de coesão derivado da existência de relaçōes funcionais, do sentido de pertencer a uma demarcação político-administrativa ou do fato de compartilhar uma determinada imagem turística [tradução livre nossa].

O interesse do autor se centra na consideração da região turística como realidade territorial sobre a qual se desenvolve um tipo de atividade que cumpre uma função significativa, tanto do ponto de vista da organização territorial como da estrutura econômica associada, para melhor compreender a forma e os impactos da implantação do turismo nos espaços regionais.
Nessa concepção, o conceito de região turística adequa-se aos postulados da regionalização, a partir da noção de espaços econômicos dotados de um certo grau de homogeneidade, que deu lugar ao conceito de regiões econômicas homogêneas, sustentadas na especialização econômica em uma determinada atividade produtiva, bem como em suas repercussões na organização territorial.

A vinculação da ordenação territorial com a atividade turística é evidente, na medida em que o turismo desempenha um papel fundamental na organização territorial e, por sua vez, o território constitui um recurso essencial para a produção e o consumo turísticos. Portanto, resulta totalmente lógico que a região turística, derivada do conceito genérico de região geográfica e concebida como um espaço diferenciado, como conseqüência da implantação territorial do turismo, constitua um conceito útil para o planejamento e a gestão do turismo [tradução livre nossa] (Ivars, 2003).

O conhecimento da realidade do turismo evidencia, conforme Vera Rebollo (1997), que as atividades turísticas não se distribuem no espaço de forma homogênea, mas que a sua localização demonstra um determinado grau de concentração espacial. Esse aspecto deve-se, entre outras razões, ao fato de que, para viabilizar o seu deslocamento entre um centro emissor e um centro receptor, o consumidor-turista pondera, tendo como pano de fundo as variáveis restrição orçamentária, preferências de consumo e utilidade esperada, bem como a influência e o peso em seu orçamento do fator distância, em suas três manifestações: a distância-física, a distância-tempo - incluindo o custo de oportunidade - e a distância-custo.

Concordando com Furió Blasco, Vera Rebollo (1997) comenta que

a apropriação e a acumulação dos benefícios [e lucros] e das utilidades turísticas, tanto empresariais como sociais, é possível graças à localização das atividades turísticas próximas [...] aos atrativos turísticos naturais, mas também aos culturais ou artificialmente criados. [...] Produzem-se [dessa forma] a funcionalização de um espaço geográfico e a configuração de um novo espaço econômico: a geração de um território especializado no sistema turístico [grifo nosso] [tradução livre nossa].

Com a funcionalização turística, conforme Furió Blasco (1994), o espaço adquire duas formas de valores: uma, como valor de uso (por exemplo, residência secundária), e outra, como meio de produção, destinada, por sua vez, a produzir novos valores de troca (por exemplo, conjuntos localizados de hotéis, apartamentos de aluguel etc.), de maneira que a combinação entre o tipo de espaço produzido e a classe ou tipo de turista que se dirigir a ele implicará a especialização particular de cada zona. 
Do "espaço turístico" partem os fluxos econômicos, positivos e negativos, que se mantêm com o espaço restante. Em outros termos, o "espaço turístico" é o centro nodal do "território turístico", pois, a partir do mesmo, tomam corpo os processos de polarização, difusão e rechaço das atividades econômicas. As forças que emanam do "espaço turístico" são as organizadoras econômica e socialmente do conjunto do sistemaespacial do turismo [o território turístico] [tradução livre nossa] (Furió Blasco, 1994).

Vera Rebollo (1997) afirma que "o turismo não é uma atividade econômica, mas uma atividade de caráter espacial que induz ou gera 'diversas' atividades econômicas" [grifo nosso] [tradução livre nossa]. Nesse contexto, o espaço assume relevante função para o turismo, como suporte, recurso e fator.

O espaço é suporte e fator por sua condição geográfica: magnitude espacial e atributos de caráter qualitativo, que têm um valor intrínseco - seja natural ou cultural -, e o derivado da valoração qualitativa que lhe outorga a sociedade em cada momento histórico. Esta valoração social conduz à "adequação" dos recursos ou atrativos e à sua conversão em produto e oferta, objeto da venda e consumo turísticos [grifo nosso] [tradução livre nossa].

Desse modo, fica clara para o autor a relevância do território como fundamento do recurso turístico e configurador do produto turístico e, conseqüentemente, como espaço de produção e espaço de consumo do fenômeno do turismo.

\section{Região polarizada - o modelo do pólo de crescimento e o turismo}

François Perroux elaborou a Teoria da Unidade Econômica Dominante, que, após anos de refinamentos e mudanças, passou a ser conhecida como Teoria dos Pólos de Crescimento.

[O pólo de crescimento] surge devido ao aparecimento de uma indústria motriz, considerando como tal aquela indústria que, antes das demais, realiza a separação dos fatores da produção, provoca a concentração de capitais sob um mesmo poder e decompõe tecnicamente as tarefas e a mecanização (Andrade, 1987).

De acordo com Tolosa (1972), para Perroux, uma indústria motriz apresenta três características principais:
[...] em primeiro lugar possui grande porte, [...] deste modo, suas decisões tendem a causar um grande impacto na área. Segundo, a indústria motriz apresenta uma taxa de crescimento superior à média regional. [...] Finalmente, a indústria motriz caracteriza-se por uma forte interdependência técnica (linkages), com uma gama diferenciada de outras indústrias, de modo a formar um complexo industrial. [...] A influência da indústria motriz pode ser basicamente dividida em efeitos sobre a estrutura de produção e efeitos sobre a demanda ou mercado.

Conforme o autor, a indústria motriz, atuando para obter matérias-primas, atrair mão-de-obra e produzir, funciona como agente de dinamização da vida regional, provocando a atração de outras indústrias, criando aglomeração populacional, o que estimulará o desenvolvimento de atividades primárias fornecedoras de alimentos e matérias-primas, bem como a formação de atividades terciárias proporcionais às necessidades da população que se instala em seu entorno.

A área de influência de um pólo, a região polarizada, depende da intensidade de dois tipos opostos de forças, as que atuam no sentido de convergência para o pólo - as forças centrípetas - e as que agem no sentido de afastamento do pólo as forças centrífugas.

Dentro da perspectiva do desenvolvimento regional, menciona-se a noção de pólo turístico adotada por Sessa (1983), que se apóia na Teoria do Pólo de Crescimento, de Perroux.

A economia nacional em crescimento não é unicamente um território politicamente organizado. É, também, uma combinação de conjuntos, relativamente ativos, representados pela indústria motriz ou pólos industriais ou atividades geograficamente aglomeradas, e de conjuntos relativamente passivos, representados pela indústria não-motriz ou regiōes dependentes, nas quais as primeiras produzem fenômenos de crescimento sobre as segundas. Uma atividade é motriz quando exercita efeitos a montante e a jusante, aumenta as aquisições de produtos intermediários de outras unidades e as aquisiçōes de serviços do trabalho e do capital, enquanto aumenta, possivelmente a um custo-preço reduzido, os produtos consignados às outras unidades e ao consumidor. A unidade motriz age de maneira positiva, no sentido de mudar as estruturas pré-existentes, incrementando o produto real, global e líquido, do conjunto econômico.

Assim, segundo o autor, distinguem-se dois tipos fundamentais de pólos: os de caráter industrial e os de caráter urbano.

Sessa toma o modelo teórico de Perroux pensando na inserção de um outro pólo de desenvolvimento, aliado aos pólos industrial e urbano: o pólo turístico. $\mathrm{Na}$ relação que efetua, ele aponta como uma das características da indústria hoteleira 
- a qual toma como referência por considerá-la a essência da atividade turística a de reunir uma série de atividades complementares que estão na origem de uma série cumulativa de ganhos e de custos em uma determinada localidade turística, o que corresponde ao efeito de "aglomeração".

Como uma conseqüência da instalação turística, surge o efeito de "conjugação", em face da necessidade de uma série de meios de transporte, desde quando, conforme Sessa, comumente, a localidade turística situa-se fora dos pólos industriais ou urbanos, originando, assim, um processo cumulativo de expansão das ofertas e demandas. Os circuitos monetários dos fluxos de turistas incrementariam uma série de dinamismos de expansão, além do âmbito da própria localidade turística.

Fundamentando a sua argumentação, Sessa informa que o pólo industrial é, habitualmente, formado por uma grande unidade motriz que apresenta efeitos de dominação sobre as outras unidades. Já o pólo turístico é formado por um conjunto de unidades motrizes representadas pelas empresas hoteleiras, que, em especial por sua ação, apresentam efeitos indubitáveis sobre todas as outras empresas de caráter colateral, comercial, de divertimento e esportivas.

Andrade (1987) menciona que, “[...] à primeira vista, pode parecer inadmissível que se fale em pólos turísticos, de vez que é estranho que possa o turismo funcionar como atividade motriz [...]". Sabe-se, no entanto, também consoante esse autor, que algumas regiões podem ter, no turismo, um importante vetor de crescimento econômico, pois, mesmo não constituindo uma atividade motriz, trata-se de uma atividade estimuladora de dinamismo econômico, possuindo um relevante caráter de transversalidade e complementaridade com diversas atividades econômicas dos setores primário, secundário e terciário, o que lhe proporciona a condição de fomentar o adensamento das cadeias produtivas que integram a estrutura produtiva das economias de tais regiões.

Ainda de acordo com Andrade, a instalação de pólos turísticos em regiões detentoras de uma atração natural, que se encontra, habitualmente, fora dos pólos urbanos e industriais, determinaria o conhecido efeito de "compensação econômica", que é um efeito de equilíbrio territorial e, portanto, macroeconômico, podendo propiciar um equilíbrio econômico entre duas zonas de um país: a urbanizada e industrial, de um lado, e a turística, de outro. O fluxo monetário derivado dos fluxos turísticos permitiria inserir essas zonas "externas" no processo de expansão acelerada do restante do país.

Já para Almeida (2002), a maioria dos atores que atuam no campo do desenvolvimento econômico ainda comunga uma visão de desenvolvimento, para ele ultrapassada, que gira em torno de dois conceitos: o "pólo" e a "cadeia de valor". Sob essa ótica, a expansão das pequenas empresas e suas redes seria uma conse- qüência do crescimento das grandes corporações associadas a esses "pólos" e aos seus "sistemas" e "cadeias de valor".

A versão tradicional do desenvolvimento regional baseado em "pólos" era uma vulgarização da teoria do pólo de crescimento, de François Perroux (1955), para quem o desenvolvimento não ocorreria de maneira uniforme numa economia, mas tenderia a se concentrar num número limitado de núcleos ou focos industriais. O desenvolvimento econômico foi definido por Perroux como a mudança estrutural provocada no espaço econômico pela expansão destes núcleos de indústrias dinâmicas. Os pólos de crescimento industrial iniciariam o processo que seria, em seguida, difundido ao resto da economia por efeitos multiplicadores e de aglomeração sobre o investimento, a renda e o emprego, incluindo a multiplicação de pequenas empresas. A teoria de Perroux se completava, assim, com a idéia de encadeamentos para frente e para trás, de Hirschman (1958). As indústrias "motrizes" eram, ainda, associadas, como lembra Pecquer (1989), à indústria pesada (siderurgia, metal-mecânica, química) [...] (Almeida, 2002)

Segundo o autor, a versão corrente do modelo de pólos representa a vulgarização da versão vulgar, em moda nos anos compreendidos entre 1970 e 1980.

Mas, hoje, fala-se de "pólos", mesmo quando se trata de indústrias leves de bens finais, de natureza footloose e, até por isso, dispersas num vasto território que, dado o seu limitado poder de "impulsão", não pretendem nem podem mudar. Fala-se, também, como Sicsúl e Lima (1997), de "pólos econômicos de base local', fundados em agroindústrias e indústrias extrativas de baixíssimo dinamismo. E, quando os grandes e tradicionais "pólos" e os novos pequenos "pseudopólos" fracassam como motores do desenvolvimento regional, exatamente porque não provocam os efeitos de encadeamento esperados, propõese o "adensamento das suas cadeias de valor" [grifo do autor] (Almeida, 2002).

A crítica realizada por Almeida quanto à vulgarização da aplicação do conceito de pólo de crescimento, de Perroux, pode ser transferida para a análise dos pólos turísticos, que constituem o eixo orientador dos planos e projetos de desenvolvimento turístico que vêm sendo elaborados no Brasil desde meados da década de 1990.

Concorda-se com a análise efetuada por Almeida, entendendo-se que sua crítica é de total pertinência, tornando evidente que a noção de "pólos turísticos" não é concernente à concepção original do pólo de crescimento de Perroux, sendo questionáveis, em razão dos diversos aspectos levantados pelo autor, os resultados de uma política pública direcionada ao desenvolvimento turístico com ênfase na implementação de "pólos turísticos", quanto ao efetivo alcance de um modelo que propicie o desenvolvimento regional de base endógena. 


\section{A abordagem territorialista e endógena no planejamento do desenvolvimento turístico regional - função versus território}

Em meados dos anos 1970, começou a se estruturar uma nova abordagem do planejamento do desenvolvimento regional, com a noção de espaço configurando-se como variável estratégica de desenvolvimento, tendo por objetivo articular estreitamente a abordagem territorial às dinâmicas de desenvolvimento regional, cujas contribuições marcantes, apontadas por Santos (2002), foram as de John Friedmann e Clyde Weaver (Territory and function, 1979), que adotaram a designação territorialista, e de Walter Stöhr e Fraser Taylor (Development from above or below?, 1981), que o denominaram from below (ascendente) a partir da base (autocentrado ou endógeno)

Walter Stöhr e Franz Todtling (Spatial equity - some antitheses to current regional development doctrine, 1977), citados por Santos (2002), chamavam a atenção para o fato de que as disparidades espaciais nos níveis de vida, num elevado número de países desenvolvidos, em vez de diminuírem, por via da aplicação de políticas regionais, aumentaram ou, pelo menos, estagnaram, sustentando que

a política de pólos de desenvolvimento ficou aquém do esperado na dinamizaçāo das periferias, gerando, mesmo, freqüentemente, efeitos perversos, dado que os efeitos negativos induzidos (polarization effects ou backwash effects) se sobrepuseram aos efeitos positivos (trickling down effects ou spread effects).

Com a crescente dificuldade em distribuir espacialmente o crescimento, dada sua inexistência ou insuficiência, "a questão fundamental para o desenvolvimento regional deixou de ser a capacidade da região para atrair novos projetos, para ser a das capacidades das regiões para gerar internamente as condições de transformação das suas estruturas produtivas" (Baptista, 1985, apud Santos, 2002).

O paradigma conceitual do desenvolvimento regional de base territorialista e endógena pressupõe que o desenvolvimento só será alcançado pela mobilização integral dos recursos das diferentes regiões para a satisfação prioritária das necessidades das respectivas populações. Seu argumento central é que o poder econômico funcional, sem um controle de um ente territorial, tende a acentuar as disparidades sociais e econômicas características do desenvolvimento polarizado. A questão-chave colocada no centro do novo modelo de desenvolvimento regional é saber "se a função deve prevalecer sobre o território ou o território sobre a função" [grifo nosso] (Friedmann \& Weaver, 1979, apud Santos, 2002).

Segundo Friedmann e Weaver (1981), atuando a doutrina dos centros ou pólos de crescimento como principal ferramenta do planejamento do desenvol- vimento espacial, este se transformou em base de apoio para a expansão do capital transnacional, fato que, inicialmente, não foi percebido com nitidez, por conta da dissimulação histórica entre integração funcional e territorial.

O planejamento foi uma funçāo da forma de governar territorialmente e, é provável, seu componente espacial teria a missāo de assegurar um modelo inter-regional equilibrado de produçāo e consumo. Pretendia-se, assim, que o planejamento espacial refletisse um objetivo público. Porém, falando praticamente, a eficácia se assentava quase sempre sobre a base de uma contabilidade de natureza privada. A questāo mais freqüente a que se chegava era até que ponto o capital privado deveria ser ajudado [traduçāo livre nossa].

Os planejadores espaciais, conforme Friedmann e Weaver (1981), podiam até reter o conceito territorial de região, mas este se configurava apenas como um rótulo para designar uma área integrada funcionalmente. O objetivo final era integrar a economia nacional sob uma forma espacialmente articulada, de modo a subordinar as economias locais ou regionais à razão do mercado nacional (e internacional).

[...] o planejamento do desenvolvimento espacial converteu-se de forma inconsciente [ou conscientemente orientado pelas elites dirigentes?] no assistente ou criado do capital transnacional. A doutrina dos centros [ou pólos] de crescimento está perfeitamente sintonizada com as reduçōes ideológicas e planificadoras das empresas multinacionais [grifo dos autores] [traduçāo livre nossa].

Diante dessa constatação, os autores propõem uma solução "agropolitana", conjugando as áreas agrícola e urbana, como uma estratégia de necessidades básicas a serem satisfeitas, conducentes ao desenvolvimento territorial.

No modelo de desenvolvimento desigual, a única forma de aumentar os mercados domésticos, conforme Friedmann e Weaver, assemelha-se à seguinte seqüência:

demanda estrangeira exportaçāo de produtos manufaturados expansāo do emprego secundário e terciário crescimento da demanda de produtos agrícolas crescimento da demanda de manufaturas domésticas crescimento da produçāo e do emprego domésticos [traduçāo livre nossa] (Paauw \& Fei, 1973 apud Friedmann \& Weaver, 1981).

Para alavancar uma produção nacional de bens intensivos em capital, a produção em massa com tecnologia avançada, exógena, deve ser limitada. O sucesso da produção local de bens intensivos em capital pode criar uma demanda por 
máquinas e equipamentos de fundamental e estratégica importância para o desenvolvimento em bases endógenas.

A nova sequência, derivada do modelo "agropolitano", na formulação dos autores, será semelhante à que segue:

aumento da produtividade agrícola + diversificação industrial em localizaçōes descentralizadas (principalmente produção de bens simples) aumento da ocupação de mão-de-obra aumento da demanda de maquinaria e equipamento [...] inovaçōes tecnológicas e de produtos aumento da capacidade de exportação de manufaturas domésticas para o mercado externo [tradução livre nossa] (Friedmann \& Weaver, 1981).

Com algum esforço de adaptação, percebe-se que as duas seqüências acima podem explicar as diferenças entre os destinos turísticos que possuem forte dependência exógena, tanto no suprimento da oferta e no conseqüente atendimento da demanda turística, como pela predominância econômica da atividade ou, mesmo, pela presença da monocultura do turismo, e os destinos que dispōem de uma diversificada estrutura produtiva e podem suprir a oferta e atender à demanda com produtos e serviços de forte conteúdo endógeno de valor agregado.

Esses dois contextos oferecem distintas perspectivas para o crescimento local ou regional e a sustentabilidade do desenvolvimento, sendo importante para o seu alcance, em bases endógenas, promover a utilização de mecanismos de autofinanciamento e a promoção do aprendizado social (Silva, 2004).

O modelo "agropolitano" é uma solução territorial para o desenvolvimento regional, no qual os interesses do território devem se impor aos interesses funcionais. Em sua abordagem, o planejamento do desenvolvimento deve privilegiar o foco no território em substituição à ênfase funcional ou espacial. "É o momento para a contenção do poder funcional e sua subordinação à vontade territorial” [tradução livre nossa] (Friedmann \& Weaver, 1981).

O planejamento territorial é uma atividade endógena. Persegue continuidades históricas, busca uma melhoria geral na qualidade de vida para toda a população da zona e exige o desenvolvimento completo do seu potencial produtivo. Seu método é holístico, multidisciplinar e complexo [grifo nosso] [tradução livre nossa] (Friedmann \& Weaver, 1981).

Friedmann e Weaver (1981) comentam que os planejamentos funcional e territorial coexistem entre si, porém em um relacionamento marcadamente conflituoso. Eles recorrem a um exemplo que, apesar de longo, se insere neste texto pela propriedade da transposição da análise que realizam, para a realidade do modelo de planejamento de desenvolvimento turístico atualmente prevalecente no Brasil, fundamentado na implantação de centros ou pólos turísticos do tipo resorts e complexos integrados de entretenimento e turismo, cuja maioria pertence a grupos de investidores nacionais e internacionais, que detêm a propriedade do capital empregado nesses empreendimentos.

Imagine-se uma planta de cimento que elege sua localização no ponto X, o ponto com menores custos totais de produção. [...] Nesta localização, que é ótima desde o ponto de vista da empresa [ou da indústria], ela empregará, digamos, cem trabalhadores retirados da zona rural e arredores. Porém, antes de finalizar sua decisão, a empresa pode regatear para conseguir benefícios adicionais, tais como isenção de impostos locais e outras ajudas, por exemplo, investimentos públicos para as estradas de acesso e para as instalaçōes da sua planta. Supondo que a empresa tenha obtido sucesso nestas negociaçōes, que a planta já esteja construída e em operação, serão impostos à comunidade custos adicionais, na forma da poluição que a planta causará, deteriorando as condiçōes higiênicas entre a população local, a destruição da vida aquática e das condiçōes recreativas, além de danos materiais significativos. Esses custos serão quase inteiramente suportados pela comunidade dentro da qual está situada a planta de cimento, mas para a qual sua única relação funcional é, por um lado, o emprego de homens e mulheres da localidade e, por outro, a maisvalia que obtém, mediante a destruição sistemática dos valores territoriais (recursos locais, tranqüilidade, beleza). Porém, e já que a localização da planta de cimento é uma decisão exógena, a escolha não necessariamente deve estar reduzida a esta localidade particular. Se a comunidade tivesse regateado mais duramente, a planta estaria buscando uma localização em um entorno político mais favorável [tradução livre nossa].

Transposto para a atividade do turismo, um cenário com essa conotação, de acordo com Silva (2004), em que se verifique a instalação de plantas turísticas sob o modelo de complexos integrados e segundo condicionantes similares às acima descritas por Fridemann e Weaver, pode acarretar um nível não-adequado de envolvimento e integração dos atores sociais das localidades onde esses empreendimentos se implantem,

fruto da dicotomia ou complementaridade disfuncional entre os fatores exógenos e os fatores endógenos implicados no crescimento do turismo, do papel desempenhado por cada grupo de fatores e da interação entre os dois grupos, influenciando e determinando o nível e a qualidade do desenvolvimento regional: com inclusão ou com exclusão social; retendo localmente ou exportando os resultados econômicos decorrentes da exploração da ati- 
vidade turística; propiciando a conservação e preservação dos recursos ambientais de base, naturais e construídos, numa perspectiva de sustentabilidade ou comprometendo tais recursos pela exploração massiva e imediatista do turismo, provocando a sua depredação e degradação.

Segundo Vera Rebollo e Marchena Gómez (1990), a necessária mobilização do potencial endógeno das regiões se une à consideração do problema regional como um problema territorial, derivando-se importantes conseqüências para o desenvolvimento turístico.

[...] desde a superação da velha idéia de que o setor industrial é o único capaz de gerar efeitos positivos sobre o desenvolvimento econômico de uma região, e considerando as possibilidades dos chamados serviços comercializáveis no desenvolvimento regional [...], o turismo é interpretado como uma riqueza regional, segundo sua aportação mais ou menos decisiva à economia da própria região, como atividade de futuro ou alavanca para a promoção do desenvolvimento regional [tradução livre nossa].

Para Silva e Perna (2002), o turismo é um fenômeno espacial cujo desenvolvimento é influenciado por variáveis econômicas, sociais, ambientais e institucionais. A dimensão espacial do turismo tem como elemento central a delimitação de um território, o qual corresponde a uma região identificada de oferta e comercialização turística. Essa região pode compreender distintas escalas: grandes espaços supranacionais, espaços nacionais, áreas regionais promocionais ou espaços locais. Qualquer que seja a escala territorial, deve existir uma unidade do fenômeno turístico em torno da comercialização de um produto ou atração dominante. Além da diferença de escala, os próprios territórios, em uma perspectiva turística, podem se encontrar em situações também distintas,

desde espaços onde o turismo não é uma atividade central [...], passando por outros onde constitui uma aposta de reconversão e modernização do sistema produtivo [...], até regiões ou locais onde o turismo constitui um pilar estrutural do desenvolvimento econômico e social [...].

Desse modo, nem todas as regiões têm capacidade para ser regiões turísticas. Conforme Silva (1995), as regiões podem ter o turismo como função dominante, como função estruturante, como função complementar ou como função residual, a depender de onde se localizem as atividades turísticas e da importância que assumam nas economias dessas regiões.

Para regiões economicamente deprimidas, considera-se que o turismo pode dinamizar localmente as potencialidades naturais e histórico-culturais, com a reali- dade dos problemas sugerindo, no entanto, uma intensa debilidade da totalidade dos vetores críticos para o desenvolvimento.

Os vetores estratégicos para se alterarem e se resolverem os problemas existentes nos diferentes níveis de dominância turística consistem nas principais áreas de intervenção e análise da intensidade e dos efeitos desta dominância, que são: os limites de carga das infra-estruturas básicas; as auditorias ambientais; a requalificação e diversificação dos equipamentos turísticos; e a cooperação estratégica dos vários agentes envolvidos e intervenientes no processo.

Quando se julga que o turismo pode assumir uma função potencialmente dominante, a médio e longo prazo, as intervenções devem ter um caráter obrigatório e aprofundado de planejamento, de ordenamento e de avaliação ex-ante, on-going e ex-post, dos efeitos dos programas e investimentos turísticos.

\section{Conclusão}

Recorre-se mais uma vez a Friedmann e Weaver (1981), buscando-se contextualizar o papel do Estado na função de captar investimentos exógenos ao âmbito local e regional, concedendo facilidades e assumindo uma série de ônus que impõem custos à sociedade e ao território envolvidos no processo de planejamento do desenvolvimento.

[...] O que se pode esperar é que o balanço de custos e benefícios [dos investimentos de origem exógena realizados em um determinado território] se incline em alguma medida em favor da comunidade local, mas isto pode requerer uma ação adequada por parte do Estado. O Estado tem, sem dúvida nenhuma, o poder de modificar a incidência dos custos da comunidade para os produtos (e também para o consumidor do produto final), mas a extensão em que pode fazê-lo depende de variáveis, tais como a natureza da atividade em questão, a existência de localizações alternativas, a propriedade do capital, as necessidades econômicas das localidades, a natureza e dimensão dos custos sociais gerados na produção e outras. Mais ainda, tal mudança pode piorar a taxa de crescimento econômico. A extensão em que isto representa uma consideração relevante, por que não dizer decisiva, só pode ser determinada desde uma perspectiva territorial.

A determinação dos custos sociais e sua incidência requerem o planejamento territorial. As necessidades territoriais devem ser articuladas cuidadosamente e deve-se considerar a base territorial dos recursos [tradução livre nossa].

Quando se refere aos pólos ou complexos industriais, a participação motora dos Poderes Públicos está na base de seu deslanche e implementação, podendo 
envolver a disponibilização de área física, de infra-estruturas, de suporte tecnológico e, inclusive, de atividades de promoção.

No caso do turismo, essa lógica pode ser percebida na execução do atual modelo brasileiro de planejamento do desenvolvimento turístico, focado na implementação de pólos turísticos regionalizados. Isso porque o arranjo institucional subjacente a tal modelo contempla uma dependência da atração de capitais privados, nacionais e internacionais, de uma prévia, adequada e custosa realização de investimentos infra-estruturantes por parte do Poder Público, implicando, ainda, o endividamento externo dos estados envolvidos, em decorrência dos financiamentos contratados com organismos internacionais.

A responsabilidade por qualificar a oferta de produtos, serviços e recursos humanos seria prioritariamente da iniciativa privada, que deveria investir recursos nesse sentido, conforme as necessidades levantadas, enquanto ao governo, também prioritariamente, caberia prover a infra-estrutura básica.

Considerando-se que a qualificação da oferta estará dada, em primeira instância, pela própria base infra-estrutural, possibilitada pela injeção de recursos de natureza pública, da qual usufruem os empreendimentos receptivos e de entretenimento de natureza privada, que, para se estabelecerem, ainda recorrem a financiamentos sustentados com recursos públicos e se beneficiam de facilidades fiscais, há, de fato, a confirmação da lógica empresarial privada de só participar se puder privatizar ou internalizar uma parte dos ganhos, ou, poder-se-ia dizer, se houver perdas, e que estas sejam internalizadas pelo governo, caracterizando-se, assim, o rent seeking behaviour, com pequenos grupos privados privilegiados se beneficiando de recursos e benefícios públicos, em detrimento do interesse coletivo maior e sem resultados muito significativos em termos do desenvolvimento local e regional de caráter endógeno.

Parafraseando Almeida (2002), pode-se inferir que essas disfunções são próprias da adoção de um modelo - o dos "pólos turísticos", que se configura como mais uma vulgarização da versão vulgar da Teoria dos Pólos de Crescimento, de François Perroux.

Desse modo, entende-se o modelo territorialista e endógeno de desenvolvimento regional como sendo mais apropriado para efeito do planejamento do desenvolvimento turístico, com o território devendo prevalecer sobre a função, que a ele deve estar incorporada e, nessa dimensão, ser analisada.

Nesse contexto, deve-se eleger a especialização produtiva - o turismo-como elemento representativo das explicações do desenvolvimento econômico de base local e regional, informadas por uma perspectiva funcional, sem negligenciar-se, no entanto, que o alcance e a sustentação do desenvolvimento resulta da interação entre a função e o território, atrelada ao nível de endogeneização dos benefícios sociais e econômicos propiciados pela atividade turística, o qual irá resultar da consideração prioritária e do aproveitamento em larga escala de recursos locais no processo de planejamento do desenvolvimento regional.

\section{Referências bibliográficas}

ALMEIDA, Paulo. 2002. Pequena empresa e desenvolvimento local: os limites da abordagem competitiva. In: FISCHER, Tânia (Org.). Gestão do desenvolvimento e poderes locais: marcos teóricos e avaliação. Salvador: Casa da Qualidade. p. 245-260.

ANDRADE, Manuel. 1987. Espaço, polarização e desenvolvimento: uma introdução à economia regional. São Paulo: Atlas.

FRIEDMANN, John \& WEAVER, Clyde. 1981. Territorio y función: la evolución de la planificación regional. Madrid: IEAL.

FURIÓ BLASCO, Elies. 1994. Turismo y territorio. Interrelación entre la función y el territorio a partir del enfoque de enlaces. 997 f. Tesis (Doctorado en Ciencias Económicas) - Facultat d'Economia, Universitat de València, València.

IVARS, Josep. 2003. Planificación turística de los espacios regionales en España. Madrid: Síntesis. LOPES, Antonio. 2002. O espaço econômico. In: COSTA, José (Coord.). Compêndio de economia regional. Coimbra: APDR. p. 35-59.

SANTOS, Domingos. 2002. A perspectiva territorialista. In: COSTA, José (Coord.). Compêndio de economia regional. Coimbra: APDR. p. 218-228.

SESSA, Alberto. 1983. Turismo e política de desenvolvimento. Trad. Lourdes Fellini Sartor. Porto Alegre: Uniontur. $167 \mathrm{p}$.

SILVA, João \& PERNA, Fernando. 2002. Turismo e desenvolvimento autosustentado. In: COSTA, José (Coord.). Compêndio de economia regional. Coimbra: APDR.

SILVA, João. 1995. Turismo como atividade econômica sustentada. In: SEMINÁRIO INTERNACIONAL DE tURISMO E DESENVOLVIMENTO, Canela, RS. Mimeografado.

SILVA, Jorge. 2004. Turismo, crescimento e desenvolvimento: uma análise urbano-regional baseada em cluster. 480f. Tese (Doutorado em Ciências da Comunicação; Área de Concentração: Turismo) - Escola de Comunicações e Artes da Universidade de São Paulo. São Paulo.

TOLOSA, Hamilton. 1972. Pólos de crescimento: teoria e política econômica. In: HADDAD, Paulo (Ed.). Planejamento regional: métodos e aplicação ao caso brasileiro. Rio de Janeiro. p. 189-243.

VERA REBOLLO, J. (Coord.). 1997. Análisis territorial del turismo. Barcelona: Ariel.

VERA REBOLLO, J. \& MARCHENA GÓMEZ, Manuel. 1990. Turismo y desarrollo: un planteamiento actual. Papers de Turisme, 3, p. 59-84.

Recebido em: 03/01/2004 (1 $1^{\mathfrak{a}}$ versāo) e 23/02/2005 (2 versão)

Aprovado em: 12/03/2005. 